\title{
Integrating History of Mathematics into the Classroom: Was Aristotle Wrong?
}

\author{
Regina M. Panasuk ${ }^{1, *} \&$ Leslie Bolinger Horton ${ }^{1}$ \\ ${ }^{1}$ Graduate School of Education, University of Massachusetts Lowell, Lowell, MA 01854, USA \\ *Corresponding author: Graduate School of Education, University of Massachusetts Lowell, 61 Wilder Street, \\ O'Leary 526, Lowell, MA 01854, USA. Tel: 1-978-943-4616. E-mail: regina_panasuk@uml.edu
}

Received: June 22, 2013

doi:10.5430/jct.v2n2p37
Accepted: July 7, $2013 \quad$ Online Published: July 30, 2013

URL: http://dx.doi.org/10.5430/jct.v2n2p37

\begin{abstract}
This article describes a part of a large scale study which helped to gain understanding of the high school mathematics teachers' perceptions related to the integration of history of mathematics into instruction. There is obvious lack of correspondence between general perception about possible benefits of students learning the history of mathematics and teachers' perceptions of the integration of the history of mathematics in curriculum. A total of 367 mathematics teachers from one of the New England states, USA, participated in an on-line comprehensive survey, which was designed by the researchers.

We report on several factors that affect teachers' decision whether include history of mathematics into curriculum, offer some recommendations for teacher professional development and suggestions for further research.
\end{abstract}

Keywords: history of mathematics; high school teachers' perceptions

"If you would understand anything, observe its beginning and its development." Aristotle

\section{Introduction}

$(384-322$ B.C.)

Throughout history humanity has collected an endless record of useful methods of calculation, techniques for solving problems, tools for surveying and measurement, logical problems and proofs. Yet rarely do we observe in the classroom the use of the remarkable method of false positions invented by Egyptians, or Euclid's algorithm for finding greatest common factor without division. Such examples of great achievements in mathematics seem worthwhile to encourage appreciation of mathematics, as well as to demonstrate how History of Mathematics (HOM) provides conditions for gaining a rich experience and understanding of the development of mathematical concepts and their connections and interrelation. Nationwide professional councils (e.g., National Council of Teachers of Mathematics (NCTM), National Research Council (NRC) and National Council for Accreditation of Teacher Education (NCATE)) acknowledge the importance of the HOM in the school curriculum. The NCTM/NCATE Program Content Standards (2003) require all prospective mathematics teachers to "Demonstrate knowledge of the historical development" of number and number system, of Euclidean and non-Euclidean geometries, algebra, calculus, discrete mathematics, statistics and probability, measurement and measurement systems, and knowledge about contributions from diverse cultures" (NCTM/NCATE, 2003).

Furthermore, NCTM (NCTM, n.d.) co-supports a professional development scholarship emphasizing the history of mathematics and its importance and significance for learning mathematics.

Few research studies and scholarly writings (e.g., Swetz, 1994, Swetz et al 1995, Siu, 2004; Weng Kin, 2008) enthusiastically argue that the history of mathematics supplies endless opportunities to trace the roots and development of humanity, development of civilizations, and is likely to make an effect on students' perception of the power of mathematics.

We concur with Wilder's (1968) belief that mathematics is a "cultural phenomenon" (p.xi), and that meaningful learning of school mathematics must be facilitated by studying the cultural significance of mathematics, the role of the 
evolution of mathematical concepts and scientific discoveries. At the same time, we are concerned that teaching mathematics in total isolation from its history impoverishes the learning of mathematics, and deprives students from the exposure to such cultural phenomenon developed over the centuries.

Empirical studies focused on teachers' perceptions of HOM (e.g., Philippou \& Christou, 1998; Schram, Wilcox, Lapan \& Lanier, 1988; Siu, 2004; Smestad, 2009; Stander, 1989) found that introducing teachers to the HOM activated their interests in the significance of mathematics and its history for learning the discipline. In parallel, the studies clearly indicated in spite of the peak in personal interest in HOM, these teachers did not express intentions of giving consideration to the inclusion of the HOM into their curriculum. All the above led us to launch a study which examined high school teachers' perceptions of the nature of mathematics. In particular, we were interested in causes of apparent lack of the HOM integration into classrooms.

We operated under several assumptions. First of all, tracing the intellectual development of humankind by learning about the evolution of at least some mathematics concepts, students would have an opportunity to link the remarkable individuals, who tirelessly contributed to the development of the structure and language of mathematics to the concepts the students learn in school. If students perceive mathematics as a set of discrete topics with no historical background or discussion of historical significance, it is likely they will fail to see the connectedness and relevance of topics within mathematics and among related sciences. Krathwohl, Bloom, and Masia (1973) argued that when students are exposed to varied experiences related to the cultural and historical aspects of evolution of mathematics, they are likely to develop an appreciation of mathematics and its role in the development of our society.

We believe that a historical background provides a perspective that lays a foundation for learning. The HOM may be viewed as a window into the theory of the subject and is likely to provide a non-threatening opportunity for entry learning of mathematics. In particular, it may be beneficial to the student whose learning of mathematics is a struggle. Knowing that in the earliest stages of invention, many of the mathematical concepts were extremely difficult to refine, understand and accept for even the most gifted mathematicians. As an example, it is well known fact that Diaphantus rejected negative numbers and called them absurd. While as early as the seventh century different civilizations in the Middle East used negative numbers to represent debts and positive numbers to represent assets, later on in the seventeenth century in Europe, Descartes rejected negative roots of equations and called them 'false' numbers, Pascal regarded the result of subtraction of a whole number from zero as nonsense, and Arnauld argued against negative numbers because in his view they created dissonance in the theory of proportions.

We were inspired by the work of Thomas Kuhn (1996) who encouraged the interest in the history of science. Of a particular significance is Kuhn's claim of the importance of the history of science for philosophy of science. He begins his famous book, The Structure of Scientific Revolution (1996) with this remarkable statement, "History, if viewed as a repository for more than anecdote or chronology, could produce a decisive transformation in the image of science by which we are now possessed" (p.1). If history of the discipline is proving to be important in the natural sciences, why should it not also be true of mathematics? The practice and sole focus on presenting mathematics as strictly useful tool may be delimiting its value and relevance beyond methods of calculation and correct answers. If the HOM provides the potential of introducing students to various dimension of learning mathematics, the question remains: Why would teachers not include it in their curriculum?

\section{Method}

To gain understanding of the high school mathematics teachers' perceptions related to the integration of the (HOM) into their instruction, a comprehensive survey scale instrument was designed to collect multifaceted data. In this paper, we describe only one part of the study, which was centered about those factors that encourage or discourage high school teachers' choice to customarily include the HOM in their mathematics courses.

\subsection{Participants}

The participants of this study were high school mathematics teachers from one of the New England states, which had 372 operating public high schools including charter schools with approximately 3,000 mathematics teachers. A total of 367 teachers responded to an invitation and participated in the on-line survey, which is about $12 \%$ of all high school mathematics teachers in the state.

\subsection{Instrument}

The entire survey contained 110 statements, which were broken into six interrelated parts. Some statements were formed by the researchers; some were adopted with substantial modification from surveys of previous studies (Tapia \& 
Marsh, 2004; Dutton, 1962; Shulman, 1986; Alken, 1974; Charalambous, Panaoura \& Philippou, 2009; Tzanakis, Arcavi, Correia de Sa, Isoda, Lit, \& Niss, 2000). Approximately $10 \%$ of the items were extracted from the NAEP Mathematics Teacher Background Questionnaire (2009). We also collected extensive demographic data that included the teachers' experience, education background, the types of teacher license, etc. Analysis of other items had been reported in other publications.

A Likert scale consisted of 5 declarative sentences with choice responses varying in degree from strongly disagree with value of 1, disagree, neutral, agree, to strongly agree with value of 5 . The inclusion of the HOM into instruction was the major focus and the background of all questions. Given the 'Yes' or 'No' type of responses, a custom path of the survey was designed to direct teachers to questions that clarified teachers' perceptions on the use of HOM.

\subsubsection{Reliability Analysis and Scales Formation}

A small pilot study with 12 high school mathematics teachers was conducted in order to gain information on quality of construction of the survey and determine its validity. We ensure that the pilot study group and the participants of the study were mutually exclusive. Seventy four Likert (ordinal) questions of the survey were used to run a reliability analysis, which yielded a Cronbach's alpha value of .94, which is indicative of a relatively high internal consistency.

\section{Results}

We report here on whether teachers' perceptions of the utility and importance of HOM influence their decision to incorporate HOM in their instruction.

Thirty (30) participants $(\approx 8 \%$ of the total $N=367$ ) left blank the question of whether they include the HOM. Table 1 (shows that one hundred and thirty three (133) teachers $(\approx 39 \%$ of the total number of participants who responded to the question, $N=337$ ) reported that they do not include HOM into their instruction. Two hundred and four (204) teachers $(\approx 61 \%$ of the total number of participants who responded to the question, $N=337)$ indicated that they do include HOM into classroom instruction.

Table 1: Summary on the 'Yes'/'No' to Inclusion of HOM

\begin{tabular}{llll}
\hline & & Frequency & Percent \\
\hline Valid & .00 & 30 & 8.2 \\
& No & 133 & 36.2 \\
& Yes & 204 & 55.6 \\
& Total & 367 & 100 \\
\hline
\end{tabular}

\subsection{Factors that Affect Teachers' Decision}

Teacher views on mathematics as a discipline and mathematics teaching are the most critical factors, which affect their decision about curriculum and teaching methods. According to Thom (1973), “...whether one wishes it or not, all mathematical pedagogy, even if scarcely coherent, rests on a philosophy of mathematics" (p. 204). Cooney, et al (1988) suggested that teachers' views, beliefs and preferences about mathematics influence their instructional practice, thus we claim that the decision of whether or not to integrate the HOM into the classroom falls into this category. Stipek, Givvin, Salmon, Valanne, and MacGyvers' (2001) findings indicate that teachers had a fairly coherent set of beliefs, which predicted their instructional practices.

In other words, if the teachers' views on the nature of mathematics impact their pedagogy, it is reasonable to assume that the teachers' views impact, specifically, their position on the inclusion of HOM. The leading factors that affected 'Yes' group teachers' decision to include HOM are shown in the Figure 1 in descending order of modal response 


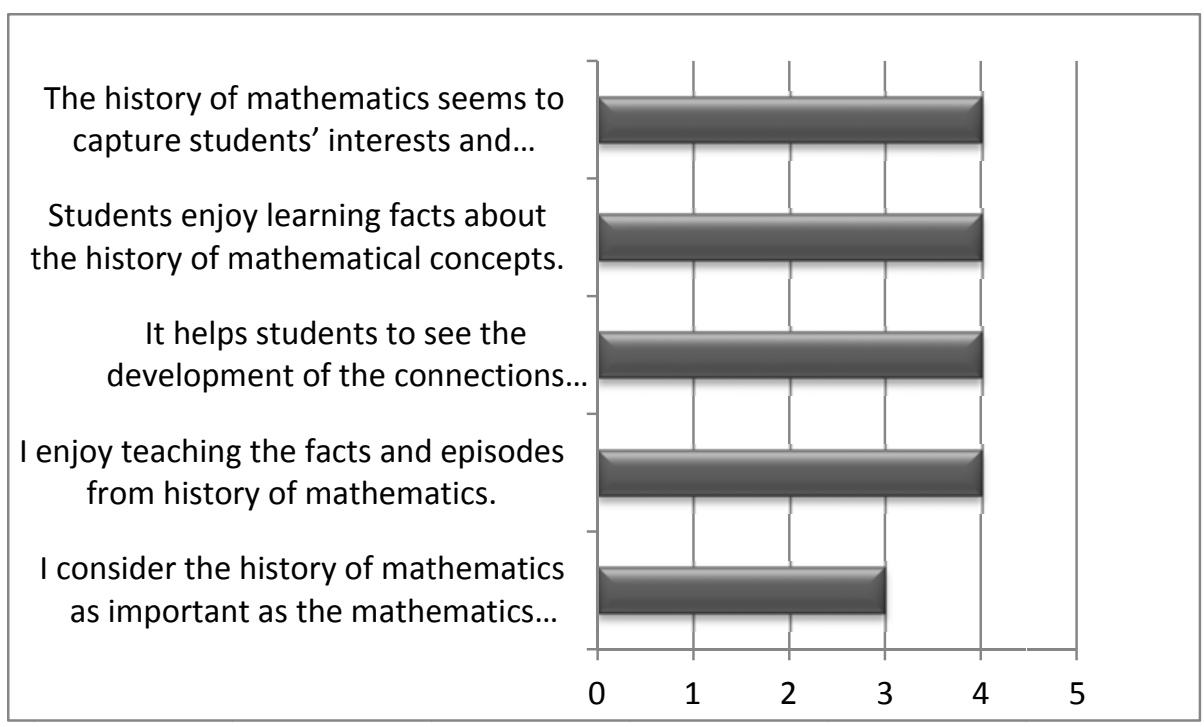

Figure 1: Teachers’ Reasons for Including HOM

The first two responses indicate that those who include HOM in their instruction apparently enjoy teaching it. Naturally, they believed that their students would enjoy learning HOM. One does not need to prove what seems to be obvious, i.e., when teachers show enthusiasm, they probably motivate students to learn and ignite their interest to the subject and its history.

The next two responses indicate that the teachers acknowledge that learning HOM may support the construction of mathematics knowledge. Apparently, the participating teachers endorsed the idea that HOM might help students to seeing connections among mathematics concepts, as well as being motivated (as a consequence of the first two factors), the students might improve their attitude toward mathematics.

The responses to the fifth factor appeared to be rather neutral. In this connection, it is worth noting that factor analysis of the survey items that focused on the teachers' perceptions about HOM, showed that the most relevant were encapsulated into five fundamental statements(Note 1). These five statements and the mean scores for the entire sample, and each group individually are shown in Table 2.

Table 2: Teachers' Perceptions of HOM

$\begin{array}{lllll}\text { All students of } & \text { History of } & \text { Knowledge of } & \text { Knowing } & \text { Understanding } \\ \text { mathematics } & \text { mathematics is } & \text { history of } & \text { history of } & \text { mathematics } \\ \text { should be taught } & \text { worthwhile } & \text { mathematics is } & \text { mathematics } & \text { would be easier } \\ \text { some history of } & \text { and necessary } & \text { valuable to } & \text { may assist } & \text { if history of } \\ \text { mathematics. } & \text { to the } & \text { non-scientists or } & \text { students in } & \text { mathematics } \\ & \begin{array}{l}\text { understanding } \\ \text { mathematics. }\end{array} & \text { non-mathematician } & \text { learning } & \text { was taught. } \\ & \text { s. } & \text { mathematical } & \\ & & & & \end{array}$

\begin{tabular}{llllll}
\hline \multicolumn{2}{l}{ 'All' teachers } & & & & \\
\hline N Valid & 347 & 347 & 347 & 346 & 346 \\
Missing & 20 & 20 & 20 & 21 & 21 \\
Mean & 3.90 & 3.46 & 3.48 & 3.81 & 3.21 \\
\hline \multicolumn{2}{l}{ 'Yes' group of teachers } & & & & \\
\hline N Valid & 203 & 203 & 203 & 202 & 202 \\
Missing & 1 & 1 & 1 & 2 & 2 \\
Mean & 4.14 & 3.74 & 3.78 & 4.03 & 3.43 \\
\hline 'No' group of teachers & & & & 132 \\
\hline N Valid & 132 & 132 & 132 & 132 & 1 \\
Missing & 1 & 1 & 1 & 1 & 2.90 \\
Mean & 3.54 & 3.06 & 3.05 & 3.48 & \\
\hline
\end{tabular}


The mean scores for 'All' teachers are significantly greater than 3 (neutral), with the exception of the last statement. There was no agreement to the statement that understanding mathematics would be easier if HOM was taught. One can hypothesize that not all teaches view HOM as a valuable teaching tool for fostering students' learning efforts. This can be, in part, due to the teacher's own perception or lack of recognition of the usefulness of HOM to the student's construction of mathematical knowledge. Clearly, the predicament is about the issue of the importance of HOM, its value and worth for the learning process of mathematics. It seems that even in the 'Yes' group some teachers did not relate the facts that helping the students to see the development of and the connections among mathematical concepts, enhancing students' interests and improving their attitude toward mathematics are closely linked and are major contributors to making it easier to understand mathematics.

The Figure 2 displays the factors that affect 'No' group. They are presented in descending order of modal response.

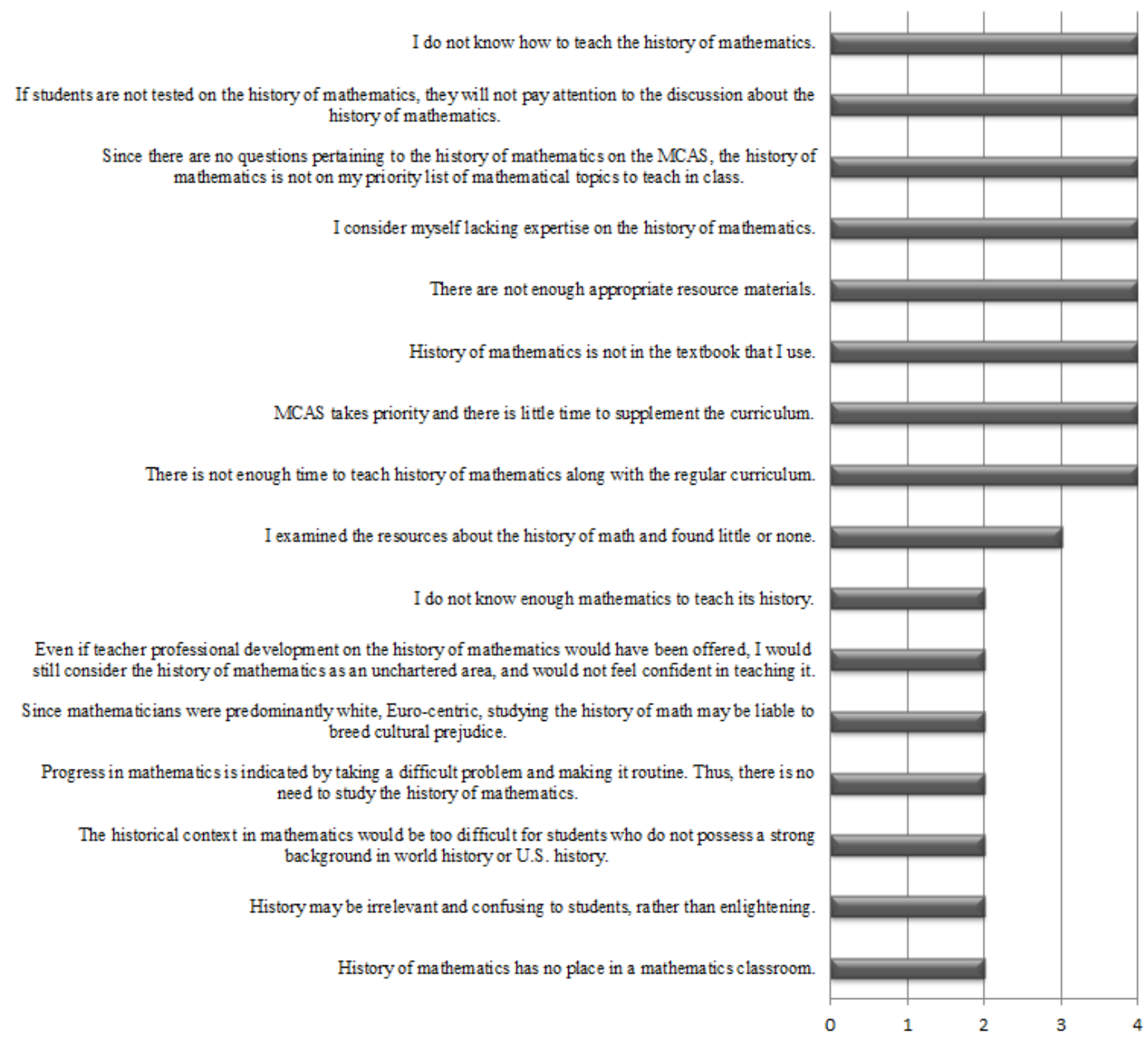

Figure 2: Factors that Affect Teachers' Decision to not Include HOM

The sequence of each statement shows the decreasing value of the explanatory factors that would encourage teachers to include HOM. The data seem quite remarkable and are addressed below. In particular, two of the factors that indicate the lack of confidence in knowledge and teaching of HOM (i.e., I consider myself lacking experience in the history of mathematics, I do not know how to teach its history of mathematics) triggered our curiosity and motivated further examination of a relationship between teachers' decision to include HOM and their formal education in the HOM. 
Table 3: Comparison between Groups 'Yes' and 'No'

\begin{tabular}{llllll}
\hline & & \multicolumn{4}{l}{ How many courses on the HOM have you taken? } \\
\cline { 3 - 6 } & & 0 & 1 & $2+$ & Total \\
\hline \multirow{3}{*}{$\begin{array}{l}\text { I include HOM } \\
\text { in my lessons }\end{array}$} & Yes & 90 & 79 & 32 & 201 \\
& & 27.2 & 23.9 & 9.7 & 60.7 \\
& No & & & & \\
& \% of total & 24.2 & 43 & 7 & 130 \\
\hline Total & & 170 & 13.0 & 2.1 & 39.3 \\
\hline
\end{tabular}

As the data show, a majority of teachers in the "No" group had no formal training in HOM and very few teachers took two or more courses on HOM. In contrast, the 'Yes' group teachers had been exposed to formal studies in HOM and a notable number of teachers took two or more courses on HOM.

We hypothesize that the more courses teachers take on the HOM, the more likely the teachers will include HOM in their instruction. These data and our speculations match the findings of the Siu's (2004) study, which investigated the value teachers place on the history of mathematics as well as their utilization of the history of mathematics in the classroom. Having approximately the same sample size $(N=360)$, Siu concluded that those teachers who were familiar with the history of mathematics through coursework had been more likely to value and use it in the classroom (p.2). Based on the above constructs and factors (Figure 1 and Figure 2), we present the following speculations and suggestions.

\section{Discussion}

We acknowledge that there are multitude factors that affect a teacher's decision whether to integrate HOM into curriculum. In the following discussion we narrowed our consideration to the following.

\subsection{Teacher Knowledge of History of Mathematics}

One of the highly ranked reason to not include HOM in mathematics curriculum is the lack of knowledge in both history of mathematics and instructional methods of teaching it. The teachers gave the highest modal rating of 4 ('Agree') to the statements, 'I consider myself lacking expertise on the history of mathematics' and "I don't know how to teach history of mathematics' (see Figure2). One can infer that there is a relationship between several factors worthy of consideration. First of all, a substantial body of research suggests that teachers' beliefs and values about teaching (e.g., Ball, 1988; Cooney, Shealy \& Arvold, 1998; Dutton, 1962; Furinghetti, 2007; Philippou \& Christou, 1998) affect their pedagogical decisions and practices. If their past learning experience did not include any exposure to HOM, the teachers may not have felt competent in teaching HOM. Naturally, they recognized a void of knowledge in HOM and thus had low confidence in teaching it. It seems quite significant that half $(51.4 \%)$ of all teachers had never taken a course on the HOM (see Table 3).

Thus, we strongly believe that every pre-service mathematics teacher must be required to take at least one full course on HOM. It is likely that learning about HOM parallel to the studies in content and pedagogy would complement the breadth and depth of mathematical content knowledge and would contribute to building confidence in teaching HOM. We hypothesize that even fragmented awareness of the chronological and epistemological development of mathematics, of some interesting events and fascinating legends and tales, would likely affect teachers' decisions to present mathematics as an exciting human endeavor rich with stories that can captivate and hold students' interests to mathematics. For example, students may be intrigued by learning stories about Pythagoras' school of thought, its remarkable discoveries of 'surreal' numbers called irrational, the cultural shock, which upset whole Greek society and led to the great expansion of the domain of numbers. The students would likely be mesmerized with the 400 years of struggle for acceptance of Hindu-Arabic base ten positional system of counting and methods of computations. We are certain that the famous 'war' in the history of mathematics between Abacists (proponents of Roman numerals) and Algorists (proponents of the Hindu-Arabic numerals) would leave nobody unmoved or indifferent. It is also feasible to assume that with increased repertoire of mathematical content knowledge and knowledge of HOM, teachers will be able to present with confidence mathematics as a continuum of concepts, rather than a collection of disjointed facts.

This data contradict the fact that indicated that the majority of the United States certification requirements for teachers at secondary schools include a course in the HOM (Katz, 1998). Based on our data we stipulate that at least half of the 
participating teachers were certified with no courses on the HOM. Searching for possible explanation and putting the pieces of the puzzle together, we analyzed the participating teachers' reflections in the open response section of the survey. It was quite enlightening to learn that some teachers preparation programs allow replacement or to 'opting out' a course on HOM. Both, the replacement or worse opting out send a message that HOM is not important for the aspiring teacher. It also provides a ground for belief that HOM is not going to be encouraged in the classroom.

From another standpoint, based on the data, $27 \%$ of the participating teachers, who never took a course on HOM, apparently considered it beneficial and included HOM in their curriculum.

We realize that it is practically impossible to empirically establish the benefit of learning HOM. However, it is equally impossible to prove the opposite. We would like to recur to the central theme of the introduction section which stresses the importance of teaching history of sciences. Why not learn from successful experiences in other disciplines and assume the benefits of learning and teaching the history in mathematics? We believe that teachers should have access to professional workshops that focus on HOM, and the methodology of incorporating HOM into the classroom. In this connection, we move on to the next factor that is closely related to the one described above.

\subsection{Resources}

In this section we address few types of resources, first and the most precious is time, second is the availability of appropriate materials, and third is the availability of and the access to the social capital, its collective value and productive benefits, which usually is embedded in teacher professional development. Classroom time, preparation time, after school time, etc are all an important entity the flow of which one cannot change, however one can find the best use of it.

Apparently, having the grade appropriate and readily available materials related to both the HOM and methodological recommendations would minimize the time the teachers would spend on searching, organizing and planning. The lack of the materials is one of the explanatory factors for the teachers who do not include HOM.

We found the two factors, knowledge about HOM and HOM resource materials, are directly connected to each other. Of course, teachers need to know the facts (e.g., the origin of the Cartesian coordinate system; preconditions and pressing importance for the invention of logarithms; the necessity to develop trigonometry) in order to plan and present those facts to the students. Thus, the material should be readily available to the teachers for their own education. Interestingly enough, we found that teachers in the 'Yes' group also indicated the lack of resources. Currently, there is an abundance of material related to numerous historical facts, biographies of famous mathematicians, and engaging stories about the influence of mathematics on the scientific, social and cultural development of civilizations. However, we found very little methodological recommendations about integrating HOM that may assist teachers. Our data showed that seventy-seven percent of the teachers responded positively to the question whether they would participate in the professional development focused on HOM. Clearly, teachers believe they may benefit from learning how to integrate HOM in their instruction. Thus, it may be suggested that professional development of all forms which include workshops, lectures, study groups, blogs, etc could serve as a means by which mathematics teachers at all levels can be engaged in discussion about teaching of HOM. Offering to teachers practical information on methods of integrating HOM may help to address the question of whether 'All students of mathematics should be taught some history of mathematics.'

The concerns about the shortage of the class time, preparation time and materials are certainly valid and must not be overlooked. Unfortunately, we found no support to the integration of the HOM in the current Common Core Standards (www.corestandards.org). The transition to the new mandated curriculum would require modification and adjustments thus more teacher time for preparation of the content. Although we find the Common Core Standards valuable and constructive, we notice that Common Core Mathematics Standards are "opting out' learning of the HOM. Any mathematics curriculum can be enriched by a short discussion about remarkable facts and stories that thousands of years of the HOM provide. For the HOM to be widely and consistently incorporated into an already prescribed curriculum, the recognition of the value in and benefits of learning HOM at all levels of K-12 must be supported by federal and state education policy makers, as well as the major national curriculum standards.

\subsection{High Stakes Testing}

The participating teachers ranked significantly high the survey items related to testing (a modal ranking of 4 'Agree'). State's high stakes testing was indicated as one of the primary reasons for teachers to not favor the integration of HOM into their curriculum. No one would questions the priority of high stakes testing. Until HOM is included as a practice standard in the mandated curriculum, many teachers would choose to not include HOM. Those who believe that integration of HOM would enrich their instruction and enhance students' engagement and motivation would probably 
consider sacrifices of the curriculum. It was quite alarming to see the 'No' group response to the second item (see Figure 2). It seems a pedagogical misconception to believe that students will not pay attention to the classroom discussion about the HOM if they are not tested on the HOM. It is clearly a matter of teacher unwillingness to facilitate interests in mathematics using seemingly simple and natural way, i.e., appealing to the historical roots of the subject. We return to the point stated in the introduction section that it is practically impossible to measure the benefit of the integration of HOM, or observe qualitatively some immediate influence or results of learning HOM. Apparently, there is no direct cause and effect relationship between learning HOM and performance in mathematics. However, the "affective domain" (Bloom, Engelhart, Furst, Hill \& Krathwohl, 1956) Bloom et al, 1956) factors such appreciation, enthusiasm, and satisfaction in learning are essential to encourage interest toward mathematics, which is considered indirect precursor of better achievement.

\subsection{Enjoyment of Teaching and Learning of HOM}

Our data analysis shows that the participating teachers established an interesting cause and effect relationship between their enjoyment of teaching HOM and their students' enjoyment of learning HOM. Also, while it may be common sense and belief that learning is affected by enjoyment, a study conducted by Stipek, et.al. (2001) showed that teachers' enjoyment of mathematics did not predict students' enjoyment (p.224). Stipek, et.al. found rather that teachers' self-confidence in their efficacy as mathematics teachers was significantly correlated with students' perceptions of their own competence as mathematics learners (p. 224). Here we offer another line of interpretation. The humanizing benefit that HOM may offer can be correlated to the affective domain of learning. We support the position of Krathwohl, Bloom, \& Masia (1973) who suggested that learning HOM might help students to better see the connections among mathematical concepts. It has a powerful potential to foster students' interests and attitude toward the subject, and likely positively affect the construction of knowledge. Some researchers (e.g., Fauvel, 1992; Furinghetti, 1997; Siu, 2004; Smestad, 2009) go as far as to assert that the HOM helps the students to form their personal and emotional connection to the subject. Teachers may have influence on students' beliefs directly or indirectly by modeling self-confidence in the subject of mathematics and in the subject of HOM. It is likely that teachers, who show high competence in subject matter content knowledge and pedagogical content knowledge (Shulman, 1986) in teaching HOM, are teachers who foster greater learning of HOM in their students. Although open to interpretation, our finding of a link between teacher and student's enjoyment suggest the value of further exploration.

\section{Conclusion}

While measuring the degree to which the above discussed factors influence the teachers' pedagogical decisions is difficult, at best, we believe that learning and teaching HOM may be a benefit to both the student and the teacher. The lack of confidence in teaching HOM is a signal for serious analysis of the school curriculum, pre-service teacher preparations, and in-service teacher professional development, and action. We assert that teaching mathematics without confidence in the historical and cognitive evolution of the subject, and the development of its concepts seems to be a lost opportunity the teacher could use to help students better learn the nature of mathematics, its cultural significance, and its influence on the technological and scientific development of the society. Given the current state of mathematics education, the need for improvement of mathematics learning and achievement, it seems critical for students to view mathematics as a dynamic body of knowledge originated by humans thousands of years ago. Teaching and learning mathematics as it is a set of discrete, unrelated topics does not contribute to the development of understanding of the value and significance of each mathematical concept, and its merit and meaning to the life of individuals and society. The HOM may serve as the foundation upon which the teacher can construct strong mathematical connections which would, in turn, help to strengthen the teacher's mathematical content knowledge and confidence (e.g., a teacher who is aware of the crisis that led to the discovery of irrational numbers, a unique development of $\pi$ and different proofs of its irrationality, would unlikely replace irrational $\pi$ with a rational 22/7).

Supporting teachers' confidence in the HOM may lead to greater integration of HOM in the classroom. Mathematics teacher programs should recognize the importance of knowing the HOM. Pre-service curriculum must be presented in a manner that allows integration and encouragement for all pre-service teachers to study HOM to learn about interconnectedness of mathematics concepts which is essential to the understanding of mathematics itself, as well as to mathematics education. We suggest a systematic professional development focused on an instructional approach of teaching HOM for in-service teachers as a follow up to the undergraduate and graduate education in the HOM. Professional development is an avenue for collaboration, study groups, learning about resources for teaching HOM, as well as an opportunity for teachers to strengthen their content and pedagogical knowledge. 
In summary, including HOM as a part of classroom instruction requires focused and consistent efforts of many parties. First of all, the teachers are encouraged to believe that integration of HOM will assist them in accomplishing their educational goals. Educators of all levels, educational administrators, policy makers, and parents are expected to encourage and support a professional standard that requires licensed teachers have a background in teaching HOM. Publishers are expected to offer materials on both the content of the HOM and methodological recommendations that can be easily integrated into classroom practice. However, to support all the above suggestions, the State frameworks should consider the inclusion of HOM as a Standard of Mathematical Practice.

\section{References}

Alken, L. R. (1974). Two scales of attitude toward mathematics. Journal for Research in Mathematics Education, 5(2), 67-71. http://dx.doi.org/10.2307/748616

Ball, D. (1988). Unlearning to teach mathematics. For the Learning of Mathematics, 8(1), 40-48.

Barbin, E., Bagni, G. T., Grugnetti, L., Kronfellner, M., Lakoma, E., \& Menghini, M. (2000). Integrating history: Research perspectives. In J. Fauvel \& J. Van Maanen. (Eds.), History in mathematics education: The ICMI study (Vol. 6, pp. 63-90). Dordrecht, The Netherlands: Kluwer Academic Publishers. http://dx.doi.org/10.1007/0-306-47220-1_3

Bloom, B. S., Engelhart, M. D., Furst, E. J., Hill, W. H., \& Krathwohl, D. R. (1956). Taxonomy of educational objectives: the classification of educational goals; Handbook I: Cognitive Domain. New York, Longmans, Green, 1956.

Charalambous, C. Y., Panaoura, A., \& Philippou, G. (2009). Using the history of mathematics to induce changes in preservice teachers; beliefs and attitudes: insights from evaluating a teacher education program. Educational Studies in Mathematics, 71(2), 161-180. http://dx.doi.org/10.1007/s10649-008-9170-0

Cooney, T.J., Shealy, B.E., \& Arvold, B. (1998). Conceptualizing belief structures of preservice secondary mathematics teachers. Journal for Research in Mathematics Education, 29(3), 306-333. http://dx.doi.org/10.2307/749792

Dutton, W. H. (1962). Attitude change of prospective elementary school teachers toward arithmetic. The Arithmetic Teacher, 9, 418-424.

Fauvel, J. (1992). Using history in mathematics education. For the Learning of Mathematics, 11(2), 3-6.

Furinghetti, F. (1997). History of mathematics, mathematics education, school practice: Case studies in linking different domains. For the Learning of Mathematics, 17(1), 55-61.

Katz, V. (1998). A History of Mathematics: An Introduction. Boston: Addison Wesley.

Krathwohl, D. R., Bloom, B. S., \& Masia, B. B. (1973). Taxonomy of Educational Objectives, the Classification of Educational Goals. Handbook II: Affective Domain. New York: David McKay Co., Inc.

Kuhn, T.S. (1996). The Structure of Scientific Revolutions. Chicago: University of Chicago Press. http://dx.doi.org/10.7208/chicago/9780226458106.001.0001

National Assessment of Educational Progress. (2009). Mathematics Teacher Background Questionnaire. Retrieved August 20, 2010, from National Center for Education Statistics Web site: http://nces.ed.gov/nationsreportcard/pdf/bgq/teacher/BQ09_teach_math_g08.pdf

National Council of Teachers of Mathematics. (2000). Principles and standards for school mathematics. Reston, VA: Author.

National Council of Teachers of Mathematics. (n.d.). Professional development scholarship emphasizing the history of mathematics for grades 6-12 teachers. Retrieved from http://www.nctm.org/resources/content.aspx?id=23623

Philippou, G. N., \& Christou, C. (1998). The effects of a preparatory mathematics program in changing prospective teachers' attitudes towards mathematics. Educational Studies in Mathematics, 35(1), 189-206. http://dx.doi.org/10.1023/A:1003030211453

Schram, P., Wilcox, S. K., Lapan, G., \& Lanier, P. (1988). Changing preservice teachers' beliefs about mathematics education. In C. A. Mahers, G. A. Goldin, \& R. B. Davis (Eds.), Proceedings of PME-NA 11 (Vol. 1, pp. 296-302). New Braunswick, NY: Rutgers University. 
Shulman, L. S. (1986). Those who understand: Knowledge growth in teaching. Educational Researcher, 15(2), 4-14. http://dx.doi.org/10.3102/0013189X015002004

Siu, M-K. (2004). No, I do not use history of mathematics in my class. Why? In S. Kaijser (Ed.), History and pedagogy of mathematics: Proceedings of HPM 2004 (pp. 375-376). Uppsala, Sweden: HPM.

Smestad, B. (2009). Teachers' conceptions of history of mathematics. Retrieved from http://home.hio.no/ bjorsme/HPM2008paper.pdf

Stander, D. (1989). The use of the history of mathematics in teaching. In P. Ernest (Ed.), Mathematics teaching: The state of the art (pp. 241-246). Philadelphia, PA: The Falmer Press.

Stipek, D., Givvin, K., Salmon, J., Valanne, J., \& MacGyvers L. (2001). Teachers' beliefs and practices related to mathematics instruction. Teaching and Teacher Education, 17(2001), 213-226. http://dx.doi.org/10.1016/S0742-051X(00)00052-4

Swetz, F. J. (1994). Learning activities from the history of mathematics. Portland, ME: J. Weston Walch.

Swetz, F., Fauvel, J., Bekken, O. Johansson., B., \& Katz, V. (Eds.). (1995). Learn from the masters. Washington, DC: The Mathematical Association of America.

Tapia, M., \& Marsh, G. E. (2004). An instrument to measure mathematics attitudes. Academic Exchange Quarterly, 8(2). Retrieved August 20, 2010 from http://www.rapidintellect.com/AEQweb/cho253441

Thom, R. (1973). Modern mathematics: Does it exist? In A. G. Howson (Ed.), Developments in mathematical education (2nd ed., pp. 194-209). New York: Cambridge University Press. http://dx.doi.org/10.1017/CBO9781139013536.011

Tzanakis, C., Arcavi, A., Correia de Sa, C., Isoda, M., Lit, C-K., \& Niss, M. (2000). Integrating history of mathematics in the classroom: an analytic survey. In J. Fauvel \& J. Van Maanen (Eds.), History in mathematics education: The ICMI study (Vol. 6, pp. 201-240). Dordrecht, The Netherlands: Kluwer Academic Publishers. http://dx.doi.org/10.1007/0-306-47220-1_7

Weng Kin, H. (2008). Using history of mathematics in the teaching and learning of mathematics in Singapore. In Proceedings of 1st RICE (pp. 1-38), Singapore.

Wilder, R. L. (1968). Evolution of mathematical concepts: An elementary study. New York: John Wiley \& Sons, Inc.

\section{Note}

Note 1 . We provide detailed analysis of these data in other publications 